\title{
Local management with methotrexate of cesarean scar ectopic pregnancy with live embryo guided by transvaginal ultrasound: $\mathbf{A}$ case report
}

\author{
Julaana de Freitas Leite ${ }^{1 *}$, Renato Fraietta², Júlio Elito Júnior ${ }^{3}$ \\ ${ }^{1}$ Specialist in Gynecology and Obstetrics - Resident in Fetal Medicine, Universidade Federal de São Paulo (Unifesp), São Paulo, SP, Brazil \\ 2PhD - Assistant Physician at the Human Reproduction Department, Unifesp, São Paulo, SP, Brazil \\ 3Habilitation (BR: Livre-docência) - Adjunct Professor at the Obstetrics Department, Unifesp, São Paulo, SP, Brazil
}

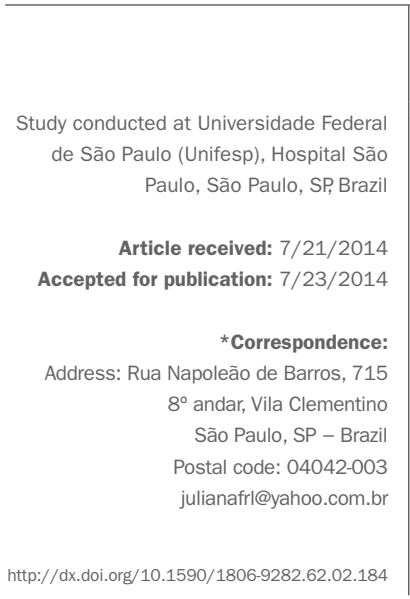

\section{SUMMARY}

Cesarean scar ectopic pregnancy is a rare type of ectopic pregnancy with high morbidity and mortality. Use of conservative conducts, including medical management with methotrexate, has avoided mutilating surgeries such as hysterectomy and spared the fertility of women. We report the case of a 30-year old patient with a cesarean scar ectopic pregnancy, with a live embryo, who was treated locally with transvaginal ultrasound-guided injection of methotrexate, complemented with various doses of systemic methotrexate.

Keywords: Ectopic pregnancy, methotrexate, scar, cesarean section.

\section{INTRODUCTION}

Non-tubal ectopic pregnancies represent less than $10 \%$ of all ectopic pregnancies, but are associated with high morbidity. ${ }^{1,2}$ Cesarean scar pregnancy is the rarest form of ectopic pregnancy. The first case was described in 1978 by Larsen and Solomon, and with increased rates of Cesarean sections in recent years, the number of cesarean scar pregnancies has increased. ${ }^{3}$ The estimated incidence is from 1 in 1,800 up to 1 in 2,216 pregnancies, with a rate of $6.1 \%$ of all ectopic pregnancies in women with history of a previous cesarean section. ${ }^{4,5}$

Cesarean scar pregnancy can cause catastrophic complications such as uterine rupture progressing with severe, life-threatening bleeding, hysterectomy and end of fertility. ${ }^{6}$ Therefore, early diagnosis performed using transvaginal ultrasound is essential for conservative treatment and the preservation of fertility in these patients.

The types of treatment are divided into surgical and non-surgical. Surgical treatment may be via uterine curettage or hysterectomy and also through uterine artery embolization. Non-surgical treatment may be expectant, medicated with systemic or local methotrexate.

Surgery is the usual conduct; however, due to the risk of mutilation, clinical treatment with methotrexate has become an important therapeutic alternative.
We report a case that was treated with local injection of methotrexate guided by transvaginal ultrasound and complemented with multiple courses of systemic methotrexate to reduce the risks of surgery and spare fertility in this patient.

\section{Methods}

The diagnosis of cesarean scar ectopic pregnancy was performed by transvaginal ultrasound according to the three diagnostic criteria described by Vial in 2000: ${ }^{7}$ the gestational sac was located between the bladder wall and anterior uterine wall, with no fetal part seen inside the uterine cavity. The third criterion was viewed through the sagittal section of the uterus in the implantation site of the gestational sac, where a discontinuity of myometrium in the anterior wall of the uterus was demonstrated.

The patient signed a consent form approved by the Universidade Federal de São Paulo (Unifesp) Ethics Committee.

Upon confirmation of the diagnosis, the conduct taken followed the protocol of the Unifesp Department of Obstetrics for non-tubal ectopic pregnancy, which is waiting when the value of $\beta$-hCG is less than $1,500 \mathrm{mIU} / \mathrm{mL}$ and declining in the interval of 48 hours; drug treatment with systemic methotrexate when the embryo does not present vitality, with multiple doses if $\beta$-hCG is higher 
than $5,000 \mathrm{mIU} / \mathrm{mL}$, and a single dose if less than 5,000 $\mathrm{mIU} / \mathrm{mL}$; drug treatment with local injection of methotrexate guided by transvaginal ultrasound if the embryo is alive, with an association made with the protocol for multiple dose of systemic methotrexate if the $\beta$-hCG value exceeds $5,000 \mathrm{mIU} / \mathrm{mL}$. In the last treatment option, methotrexate is given at a dose of $1 \mathrm{mg} / \mathrm{kg}$, initially with local injection, followed by 3 intramuscular doses on alternate days. In the days between these doses, folinic acid was administered at a dose of $0.1 \mathrm{mg} / \mathrm{kg}$ and control tests for possible methotrexate toxicity (hepatic and renal function), and $\beta$-hCG dosage are measured.

In this case report the patient presented a cesarean scar ectopic pregnancy with live embryo and $\beta$-hCG of $18,716 \mathrm{mIU} / \mathrm{mL}$. As such, local treatment with transvaginal ultrasound-guided injection of methotrexate was indicated, complemented with the protocol of multiple systemic doses of methotrexate.

Post treatment follow-up was done with weekly dosing of $\beta$-hCG up to a value of less than $5,000 \mathrm{mIU} / \mathrm{mL}$ and realization of transvaginal ultrasound until the absence of the Doppler flow.

\section{Case report}

The 30-year old pregnant patient, weighing $68 \mathrm{~kg}$, secundigravida, with previous cesarean delivery 12 years before, was 6 weeks late on her period although presenting a small amount of vaginal bleeding for 1 day. On physical examination the patient was hemodynamically stable; in the speculum examination there was the presence of vaginal bleeding collected in small quantities; and in the touch examination the cervix was impervious, with an increased uterus for 6 weeks, and palpable attachments without changes. The laboratory tests were: $\beta$-hCG of $18,716, \mathrm{mIU} / \mathrm{mL}$, blood test with hemoglobin $(\mathrm{Hb})$ of $12.8 \mathrm{~g} / \mathrm{dL}$, hematocrin (Ht) of $38.5 \%$, leukocytes of 7,450/uL, platelets of 209,000/ $\mathrm{uL}$, positive $\mathrm{O} \mathrm{Rh}$ blood typing, $0.57 \mathrm{mg} / \mathrm{dL}$ of creatinine, urea of $18 \mathrm{mg} / \mathrm{dL}$, SGOT of $26 \mathrm{U} / \mathrm{L}$ and SGPT of $28 \mathrm{U} / \mathrm{L}$.

Transvaginal ultrasound performed on this day showed a $6 \mathrm{~mm}$ crown to rump length (CRL), corresponding to gestational age of 6 weeks and 4 days, a gestational sac of $16 \times 14 \times 9.6 \mathrm{~mm}$ located at the site of the previous cesarean section scar with a live embryo (126 bpm fetal heart rate), an empty uterine cavity and attachments without changes. The gestational sac was located approximately 22 $\mathrm{mm}$ from the external orifice of the cervix (Figure 1).

Due to the presence of the live embryo, the patient was submitted to transvaginal ultrasound-guided puncture and injection of methotrexate inside the gestational sac at $68 \mathrm{mg}(1 \mathrm{mg} / \mathrm{kg})$. A 17 Gauge Cook ${ }^{\circledR}$ Medical

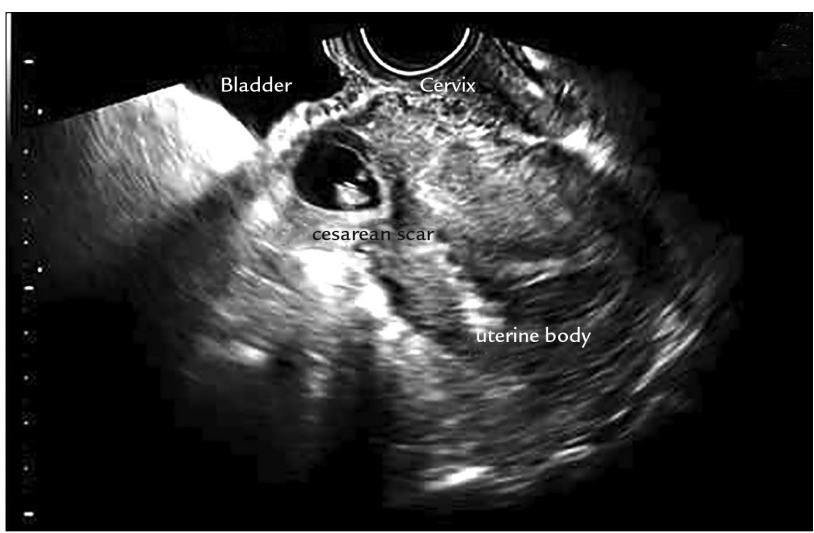

FIGURE 1 Ultrasonography showing the anatomical relationship between bladder, cervix, uterine body and gestational sac in the topography of the cesarean scar, with an empty uterine cavity.

needle was used, guided by the Aloka $500^{\circledR}$ ultrasound apparatus.

In addition to the local dose, three $68 \mathrm{mg}$ intramuscular doses of methotrexate $(1 \mathrm{mg} / \mathrm{kg})$ interspersed with 4 intramuscular doses of folinic acid at $6.8 \mathrm{mg}(0.1 \mathrm{mg} /$ $\mathrm{kg})$ were given.

The patient remained in hospital until the last dose of folinic acid without clinical complications after the procedure, showing only slight abdominal colic treated with analgesia, receiving a discharge with weekly followup at the outpatient clinic specializing in ectopic pregnancy at Hospital São Paulo (Unifesp).

It is important to note that blood test, hepatic and renal function examinations remained normal from admission to discharge from hospital.

Seven days after discharge, the patient sought the Gynecology and Obstetrics emergency service of the Hospital São Paulo complaining of vaginal bleeding. In the physical examination the patient was found to be hemodynamically stable, the abdominal examination showed no changes, the specular examination showed the presence of a discrete amount of blood collected, painless vaginal touch with impervious cervix, and intrapelvic uterus and attachments normal to the touch. The laboratory examinations on this occasion were still normal (blood, hepatic and renal function), showing that there was no methotrexate toxicity, with $\mathrm{Hb}$ of $12 \mathrm{~g} / \mathrm{dL}$ and $\beta$-hCG of $6,129 \mathrm{mIU} / \mathrm{mL}$. Another ultrasound examination was performed with uterine volume of $200 \mathrm{~cm}^{3}$ and presence of a cystic image on the anterior uterine wall with anechoic content and irregular walls, measuring $1.3 \times 1.2 \times 0.5 \mathrm{~cm}$, without characterization of an embryo, endometrial echo of $1.2 \mathrm{~cm}$ and unchanged attachments. 
The patient was advised to continue the outpatient follow-up where she remained in weekly monitoring, progressing with falling $\beta$-hCG levels. After 58 days of monitoring, the $\beta$-hCG value was negative, as displayed in the graph of the progression of this examination (Figure 2). After 3 months of treatment with methotrexate, another transvaginal ultrasound was conducted, showing the disappearance of the gestational sac (Figure 3).

\section{Discussion}

Cesarean scar pregnancy is the rarest form of ectopic pregnancy. Since the first case described in 1978 until 2001, there were only 19 cases reported. By 2006 there were 155 cases and by 2011 the number of cases described in the literature was 751, showing a rapid increase in the incidence of this type of pregnancy. ${ }^{1,8-11}$

The basis of the pathophysiology is the invasion of the blastocyst in the myometrium through minimal communication between the previous cesarean scar and the endometrial cavity. ${ }^{12}$

The cesarean scar ectopic pregnancy tends to have a more aggressive behavior because of the risk of uterine rupture and bleeding in the first and second trimesters of pregnancy. ${ }^{13}$

The risk factors are the number of prior cesarean sections, short time interval between the cesarean delivery and the current pregnancy, and retroversion of the uterus which may lead to greater cesarean scar dehiscence, in- creasing the chance of implantation of the gestational sac in this region. ${ }^{14}$

Transvaginal ultrasound allows early diagnosis of this disease before tragic outcomes such as uterine rupture or excessive bleeding and enables conservative treatment instead of mutilating surgeries such as hysterectomy, sparing fertility. ${ }^{7}$ It also allows differential diagnosis with abortion in progress, molar pregnancy and cervical ectopic pregnancy through the ultrasound diagnostic criteria proposed by Vial in 2000.

Vial et al. ${ }^{7}$ have also proposed two types of cesarean scar ectopic pregnancy: endogenous and exogenous. In the endogenous type, the implementation of the gestational sac occurs in the c-section scar with the development of the pregnancy into the uterine cavity. The exogenous type occurs with deeper implantation of the gestational sac in the cesarean scar, which with the progression of the pregnancy may lead to uterine rupture and hemorrhage in the first trimester of pregnancy.

There is still no consensus on the best mode of treatment in the case of cesarean scar ectopic pregnancy. The conduct at our service is drug treatment and outpatient monitoring with weekly $\beta$-hCG exams until resolution, only intervening surgically in the presence of heavy bleeding and under these circumstances, if possible, trying to perform uterine artery embolization prior to curettage. ${ }^{15}$

During the outpatient follow-up, the ultrasound examination is not performed routinely, and should be re-

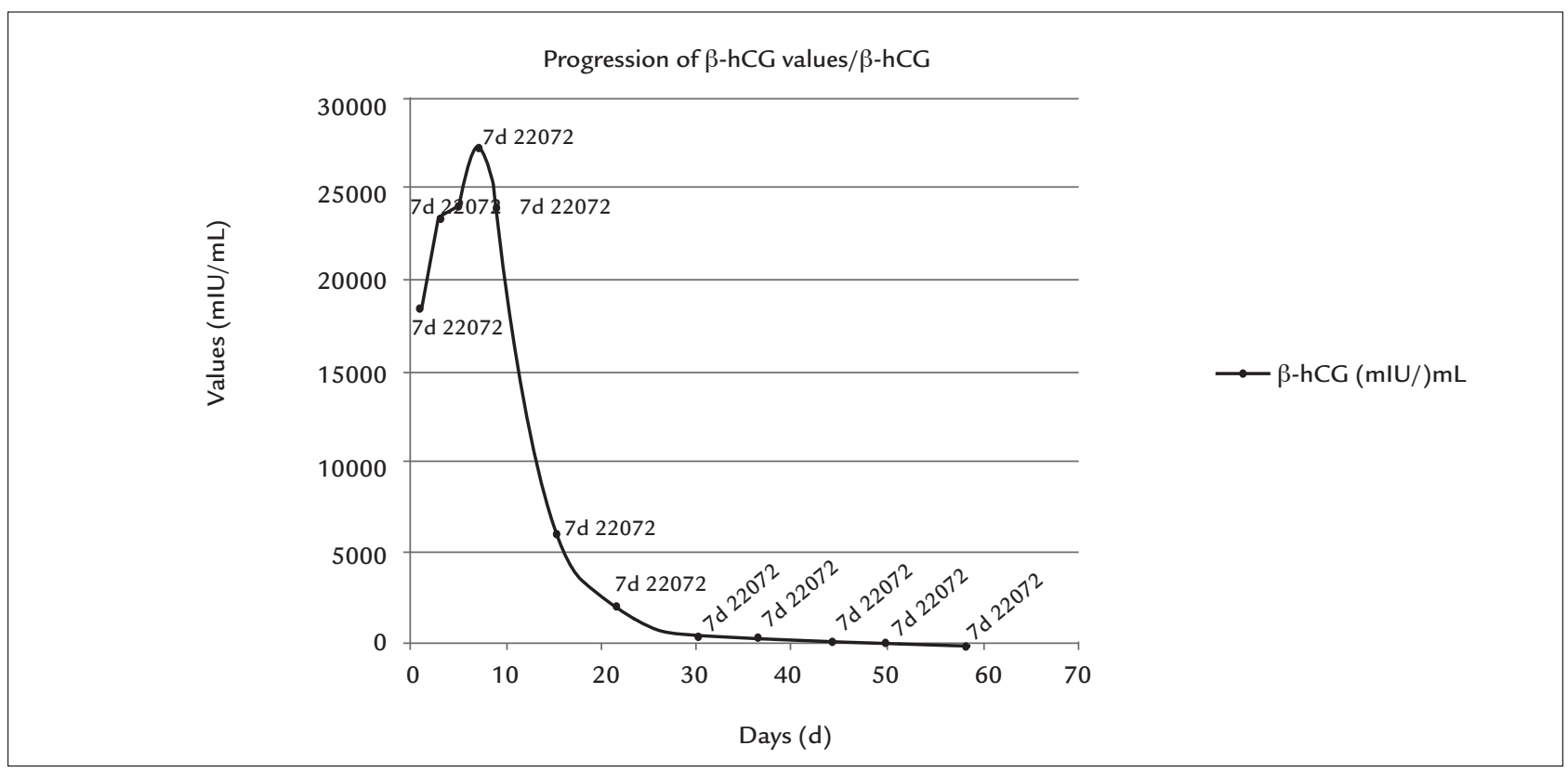

FIGURE 2 Graph with the progression of $\beta$-hCG values in the treatment of the cesarean scar ectopic pregnancy with local and systemic methotrexate in this case report. 


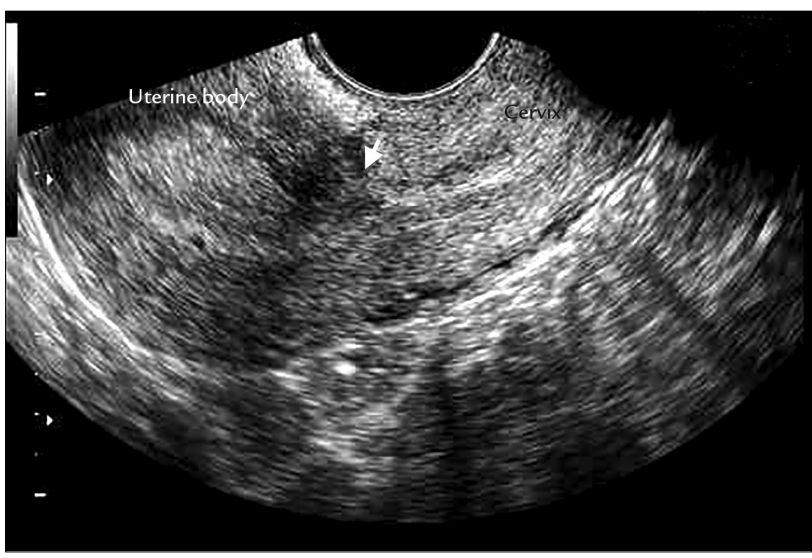

FIGURE 3 Transvaginal ultrasonography after 3 months of drug treatment with local and systemic methotrexate for cesarean scar ectopic pregnancy.

peated when $\beta$-hCG reaches a negative value or after 3 months of drug treatment. This should only be brought forward if there are new episodes of bleeding.

In our case, a surgical approach was not required, using merely drug treatment with a local dose plus three local doses of systemic methotrexate. However, a slow regression of $\beta$-hCG values was observed to the initially high values, taking 58 days to reach negative values. An Australian article about 13 cases of cesarean scar ectopic pregnancy suggests that the association of local drug treatment with systemic doses can reduce the time interval for $\beta$-hCG to become negative and that local methotrexate seems to be more effective than systemic treatment alone due to the presence of fibrotic tissue in the region of the scar, limiting the access of systemic medication. ${ }^{14}$

After 3 to 6 months of disappearance of the image of the ectopic pregnancy, our recommendation is to perform hysterosalpingography and hysteroscopy for better assessment of the uterine cavity, as well as adequate reproductive planning for these patients.

\section{Conclusion}

The early diagnosis of cesarean scar ectopic pregnancy is performed via transvaginal ultrasound and is fundamental for the indication of suitable conservative treatment. Drug treatment with a local dose of ultrasound-guided methotrexate in the presence of a live embryo, associated with a protocol of multiple doses of systemic methotrexate when $\beta$-hCG exceeds $5,000 \mathrm{mIU} / \mathrm{mL}$ has been found effective, preventing mutilating surgeries and sparing fertility in these patients.

\section{Resumo}

Tratamento local com metotrexato guiado por ultrassonografia transvaginal de gravidez ectópica em cicatriz de cesárea com embrião vivo: relato de caso

A gravidez ectópica na cicatriz de cesárea é uma forma rara de gestação ectópica com elevada morbimortalidade. $\mathrm{O}$ emprego de condutas conservadoras, como o tratamento medicamentoso com metotrexato, tem evitado cirurgias mutiladoras, como a histerectomia, e preservado o futuro reprodutivo da mulher. Relatamos um caso de paciente de 30 anos, com gravidez ectópica em cicatriz de cesárea, com embrião vivo, tratada com injeção local de metotrexato guiada por ultrassonografia transvaginal, complementada com tratamento sistêmico com múltiplas doses de metotrexato.

Palavras-chave: gravidez ectópica, metotrexato, cicatriz, cesárea.

\section{References}

1. Fylstra DL, Pound-Chang T, Miller MG, Cooper A, Miler KM. Ectopic pregnancy within a cesarean delivery scar: a case report. Am J Obstet Gynecol. 2002; 187(2):302-4.

2. Jourdain O, Fontanges M, Schiano A, Rauch F, Gonnet JM. [Management of other ectopic pregnancies (corneal, interstitial, angular, ovarian)]. J Gynecol Obstet Biol Reprod (Paris). 2003; 32(7 Suppl):S93-100.

3. Bignardi T, Condous $\mathrm{G}$. Transrectal ultrasound-guided surgical evacuation of cesarean scar ectopic pregnancy. Ultrasound Obstet Gynecol. 2010; 35(4):481-5.

4. Jurkovic D, Hillaby K, Woelfer B, Lawrence A, Salim R, Elson CJ. Firsttrimester diagnosis and management of pregnancies implanted into the lower uterine segment Cesarean section scar. Ultrassond Obst Gynecol. 2003; 21(3):220-7.

5. Seaw KM, Huang LW, lin YH, Lin MY, Tsai YL, Hwang JL. Cesarean scar pregnancy: issues in management. Ultrassound Obstet Gynecol. 2004; 23(3):247-53.

6. Herman A, Weinraub Z, Avrech O, Maymon R, Ron-El R, Bukovsky Y. Follow up and outcome of isthmic pregnancy located in a previous caesarean section scar. Br J Obstet Gynaecol. 1995; 102(10):839-41.

7. Vial Y, Petignat P, Hohlfeld P. Pregnancy in a cesarean scar. Ultrasound Obstet Gynecol. 2000; 16(6):592-3.

8. Rotas MA, Haberman S, Levgur M. Cesarean scar ectopic pregnancies: etiology, diagnosis, and management. Obstet Gynecol. 2006; 107(6):1373-81.

9. Larsen JV, Solomon MH. Pregnancy in a uterine scar sacculus - an unusual cause of postabortal haemorrhage. A case report. S Afr Med J. 1978; 53(4):142-3.

10. Timor-Tritsch IE, Monteagudo A. Unforeseen consequences of the increasing rate of cesarean deliveries: early placenta accreta and cesarean scar pregnancy. A review. Am J Obstet Gynecol. 2012; 207(1):14-29.

11. Agarwal N, Shahid A, Odejinmi F. Caesarean scar pregnancy (CSP): a rare case of complete scar dehiscence due to scar ectopic pregnancy and its management. Arch Gynecol Obstet. 2013; 288(1):231-2.

12. Ash A, Smith A, Maxwell D. Caesarean scar pregnancy. BJOG. 2007; 114(3):253-63.

13. Fylstra DL. Ectopic pregnancy within a cesarean scar: a review. Obst Gynecol Surv. 2002; 57(8):537-43

14. Michener C, Dickinson JE. Caesarean scar ectopic pregnancy: a single centre case series. Aust N Z J Obstet Gynaecol. 2009; 49(5):451-5.

15. Elito J, Araujo E, Santana EFM, Szejnfeld D, Helfer TM, Nardozza LMM, et al. Uterine artery embolization with methotrexate infusion as treatment for cesarean scar pregnancy. Med Ultrason. 2013; 15(3):240-3. 